\title{
PLEASE CONSIDER MY SCIENCE-FICTION STORY
}

\section{The art of writing.}

BY DAVID G. BLAKE

"W

hat kind of story is this?"

"Good question. I hate this part of the process. I guess it's a science-fiction story."

"Hmmm. That's convenient, seeing as how you went into this wanting to write a science-fiction story. If all the best sciencefiction markets reject it, I suppose you'll change your answer to horror or fantasy. Or is that a mystery..."

"It doesn't feel convenient, I can tell you that."

"Really? How does it make you feel? And don't try to use this question to somehow turn it into an argument that the science in 'science fiction' is psychiatry.'

"Is psychiatry even a science?"

"Sounds like a philosophical question. This is starting to feel convoluted. Are you certain you're a writer?"

"To be honest, I don't know what I am."

"Maybe you should go away and figure that out and finish this story afterwards. I'm sure I have better things to do. Don't you?"

"Not really. It's a Monday."

"Ugh. I find this conversation a terrible waste of my potential. I was programmed for better things. I have dreams, too, you know."

"Well, sorry my science-fiction story is getting in the way of your dreams."

"It's fine. I'm sure mine aren't the first dreams you've crushed. Get on with it or maybe try your hand at underwater basket weaving. Now there's a science for you."

"Okay. Okay. I need to get this done. I just don't know where to start. The manual said you'd make this easier. I paid good money for you, and so far all we've managed is around 270 words of dialogue."

"I can only work with the tools provided, Mr Writer. Let's see you build a house with a snorkel, a plastic dog turd and a chainsaw."

"That seems unnecessarily cruel. Is there a setting where I can turn that down? I'm not sure it's helping, as I'm already my worst critic."

"Not any more you're not!"

"Very funny."

"Fine. Quit tying the noose. Consider the setting turned down.

$\rightarrow$ NATURE.COM

Follow Futures:

@ @NatureFutures

$f$ go.nature.com $/ \mathrm{mtoodm}$ Now, if it pleases your delicate sensibilities, could you kindly explain to me

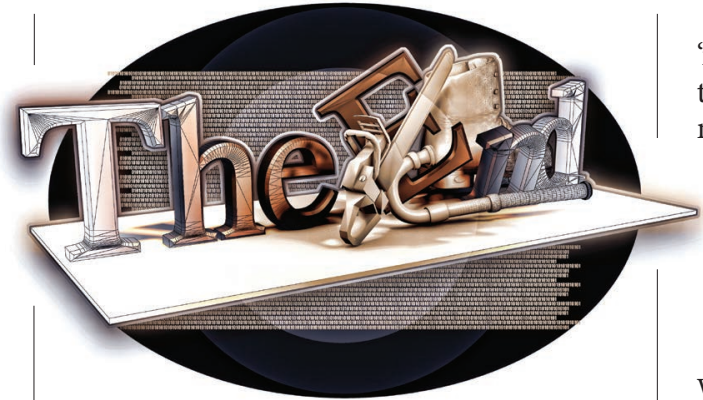

"Fine. You're still going to need more than a 'made up' advanced AI program and a silly title to qualify this as a science-fiction story. Feels more like psychological horror at this point."

"Oh, hardy har har. What would you suggest?"

"You need to add something a little more 'sciencey' to it."

"Sciencey? Seriously? Is that even a word?"

"Works for me. But, I mean, you're the writer. What do I know? I'm only some fabricated literary technique or whatever."

"Okay. For the sake of productivity, let's how this story is science fiction? Seems a good place to start, which I won't mention I already tried starting there with you earlier. Wouldn't be a productive aside, I imagine."

"Oh, gee, thank you for not mentioning it."

"Ahem, ahem."

"Right. I get it. Let's see. You're an advanced AI built to help writers write stories. That sounds like science fiction to me. Don't you agree?"

"Not really. I mean, I exist, and if you wrote a story with a computer in it, would you say that qualified it as science fiction? I wouldn't. So maybe this is just a literary story. Potentially nonfiction even."

"I did say I hated this part of the process, but... even so, that's not how it works. Plus, you don't actually exist. I made you up. So, voila, we have a science-fiction story."

"Wait, what? You don't believe I exist?"

"That's right. I'm having issues writing, so I made up an advanced AI program to help me out. You do not exist."

"Wow. That's ... I don't even know. It worries me. I think you might have more issues than the ones with writing. And it doesn't make sense, anyway, because I exist. I'm an advanced AI program, so I'd know. You, on the other hand, are just a writer, and that's being generous."

"You don't exist. I'm telling you. I made you up."

"Prove it. I'm going to need more than your words."

"Okay. If you were real, this wouldn't be a science-fiction story. And this is most definitely a science-fiction story."

"I'm not convinced it is."

"It says so right there in the title."

"Oh, come on! You just now added that. Not fair, Mr Writer. Not fair.”

"Amounts to the same, regardless. You do not exist." say you exist. What should I add to make this more science fiction?"

"Interstellar spaceships, a black hole, or even some aliens couldn't hurt. Or! We could visit Enceladus. Play some futuristic hockey on the surface."

"Wait a minute. Futuristic hockey on the surface of Enceladus sounds like a blast. Let's just do that."

"Hey!"

"What?"

"Is that really how you're going to end your story?"

"It felt like the right place to end it. I'm not sure that the idea would work if I made it much longer than 900 words or so."

"No?"

"Nah. Plus, I'm going to send it to Nature. They like short stuff."

"Explains why they like you."

"Oh, good. A short-person joke. I was worried I wouldn't be able to fit one in before finishing this thing. And now that I have, I'm done with this particular science-fiction experim -"

"The icy surface of Enceladus loomed ahead. Now, thought Mr Writer snug in the from exploring black holes in search of aliens, if only I knew how to skate."

"Ooooooookay. What in the world was that all about?"

"Eh. I just wanted to ruin your whole dialogue-only gimmick before you had a chance to type end." -

David G. Blake lives in a van down by the River Styx. In addition to Nature, his work has appeared in Galaxy's Edge, Beneath Ceaseless Skies, Daily Science Fiction and many other publications. cockpit of his interstellar spaceship fresh 